\title{
Algorithm of Treatment for Extensive Vertebral Hemangiomas According to Tomita Classification of Vertebral Tumors
}

\section{Lorenzo Nigro}

Department of Neurology and Psychiatry, Sapienza University of Rome, Rome, Italy

Corresponding author: Lorenzo Nigro, Department of Neurology and Psychiatry, Sapienza, University of Rome, Rome, Italy, Tel: 00393286617481; E-mail: nigro86@hotmail.it

Received: Apr 14, 2017; Accepted: Apr 21, 2017; Published: Apr 24, 2017

Citation: Nigro L. Algorithm of Treatment for Extensive Vertebral Hemangiomas According to Tomita Classification of Vertebral Tumors. J Neurol Neurosci. 2018, 8:2.

\section{Introduction}

Vertebral hemangiomas (VHs) are considered benign tumors consisting in vascular spaces lined by endothelium [1]. Despite this definition they may develop and become extensive and symptomatic, in these cases they are called "aggressive".

A wide range of treatment options are available for symptomatic and extensive $\mathrm{VHs}$ such as radiotherapy, radiosurgery, embolization, alcohol injection, vertebroplasty, kyphoplasty, laminectomy, intralesional resection and total en bloc spondilectomy.

Unfortunately now-a-days there is no consensus in literature regarding which is most appropriate and in which circumstances.

Dang et al. [2] proposed a symptom-based algorithm of treatment but they did not give information about the width of the lesion.

Fourney et al. [3] in a comment to the article agreed with them that the management of these tumors should be largely symptom-based because VHs are pathologically benign.

Our group recently reported a case of vertebral collapse after radiotherapy was executed for the treatment of an extensive thoracic $\mathrm{VH}$ and we proposed a new algorithm of treatment for $\mathrm{VHs}$ in which the width of the lesion was considered [4].

Perhaps our literature review demonstrated that radiotherapy is widely proposed for symptomatic VHs but its effects on the tumoral tissue are unknown and a vertebral collapse may result when applied to extensive lesions [5].

Data regarding structural changes of the lesion after radiotherapy are very limited. Vascular fibrosis that causes an impairment of circulation and an elimination of abnormal vessels is suggested to play a key role [6]. Sakata et al. did not find any changes using CT, MRI, or X-rays in a series of 14 patients even after 5 years of radiotherapy [7]. Heyd et al. described reossification in $26.2 \%$ of cases in the group of 84 patients [8]. These results are similar to those obtained by Miszczyk, $20 \%$ to $33.3 \%$ of reossification or fatty progression during their follow-ups [6]. Boschi et al. assert that radiotherapy for $\mathrm{VHs}$ carries the risk of radiation-induced secondary sarcomas or the development of radionecrosis [9].

We reconsidered and limited the role of radiotherapy and suggested it only for small tumors determining pain, without spinal canal invasion and in absence of neurological deficit. Surgery was proposed for wide tumors presenting with spinal canal invasion or in presence of neurological deficit.

In this article I would like to revise the algorithm since it did not give definition about the location of the tumor inside the vertebra.

I consider this of remarkable importance for the evaluation of mechanical instability and plan the appropriate treatment.

A revision according to Tomita classification of vertebral lesions [5] has been made (Table 1).

Table 1 The table reports the proposed algorithm of treatment for $\mathrm{VHs}$ according to the symptoms of the patient and the Tomita classification of spinal tumors.

\begin{tabular}{|c|c|c|}
\hline Symptoms & $\begin{array}{l}\text { Type of lesion } \\
\text { according to } \\
\text { Tomita } \\
\text { classification }\end{array}$ & Treatment \\
\hline \multirow{6}{*}{$\begin{array}{l}\text { Asymptomatic } \\
\text { patients }\end{array}$} & Type 1 & No intervention \\
\hline & Type 2 & No intervention \\
\hline & Type 3 & Radiological follow-up \\
\hline & Type 4 & Radiotherapy \\
\hline & Type 5 & $\begin{array}{l}\text { Vertebroplasty, alcohol ablation } \\
\text { or surgery }\end{array}$ \\
\hline & Type 6 & $\begin{array}{l}\text { Vertebroplasty, alcohol ablation } \\
\text { or surgery }\end{array}$ \\
\hline \multirow{5}{*}{$\begin{array}{l}\text { Patients affected } \\
\text { by pain }\end{array}$} & Type 1 & Radiological follow-up \\
\hline & Type 2 & Radiotherapy \\
\hline & Type 3 & Radiotherapy \\
\hline & Type 4 & Radiotherapy \\
\hline & Type 5 & $\begin{array}{l}\text { Vertebroplasty, alcohol ablation } \\
\text { or surgery }\end{array}$ \\
\hline
\end{tabular}




\begin{tabular}{|l|l|l|}
\hline & Type 6 & $\begin{array}{l}\text { Vertebroplasty, alcohol ablation } \\
\text { or surgery }\end{array}$ \\
\hline $\begin{array}{l}\text { Patients affected } \\
\text { by neurological } \\
\text { deficit }\end{array}$ & Type 4 & $\begin{array}{l}\text { Vertebroplasty, alcohol ablation } \\
\text { or surgery }\end{array}$ \\
\cline { 2 - 3 } & Type 5 & $\begin{array}{l}\text { Vertebroplasty, alcohol ablation } \\
\text { or surgery }\end{array}$ \\
\cline { 2 - 3 } & Type 6 & $\begin{array}{l}\text { Vertebroplasty, alcohol ablation } \\
\text { or surgery }\end{array}$ \\
\hline
\end{tabular}

Tomita et al. proposed a schematic classification of spinal tumors basing on their width and location inside the vertebra. They considered this classification in addition to other prognostic factors for the treatment of spinal metastasis [10].

In this algorithm the Tomita classification is used for the treatment of VHs for its feasibility in identify the vertebral lesions.

\section{Asymptomatic patients}

In Tomita classification of vertebral lesions Type 1 and type 2 tumors are quite small lesions. They are intra-compartmental and limited to the vertebral body in type 1 and intracompartmental with pedicle extension in type 2 . In this algorithm no need of any intervention is proposed for asymptomatic patients affected by these types of tumors.

Type 3 tumors are wider tumors with a body-lamina extension, however the spinal instability is usually not concerned. In asymptomatic patients affected by VHs a radiological follow-up is indicated in order to evaluate the growth of the tumor over the time.

Type 4 tumors are extra-compartmental with epidural extension. Radiotherapy can be proposed for asymptomatic patients affected by this type of tumor since the tumor presents a spinal canal invasion and may become symptomatic, the radiotherapy may determine shrinkage of the tumor and there is not concern about the spinal stability.

Asymptomatic patients affected by type 5 or 6 can be considered at risk of spinal cord compression or at risk of spinal instability since the tumor extends paravertebrally in type 5 and involves more segments in type 6 .

The risk of a vertebral collapse should be avoided in these patients and a percutaneous treatment as vertebroplasty or alcohol ablation are considered appropriate.

Fixation or adjuvant radiotherapy can be considered afterwards.

Surgery with a total or partial removal of the lesion can be proposed, but considered quite "aggressive" for asymptomatic patients.

Radiotherapy is excluded for these patients since of the risk of vertebral collapse in these extensive tumors.

\section{Patients affected by pain}

For patients affected by pain with type 1 lesion only a radiological follow-up is proposed, since the lesion is small, intra-compartmental and it is an unsure cause of pain.

Patients affected by pain with type 2 or 3 lesions can be considered for radiotherapy, since the lesion is wider and they may cause pain. The radiotherapy may alleviate the pain and the spinal instability is not concerned.

Patients affected by pain with type 4 lesions can be considered for radiotherapy, since the spinal instability is not concerned and radiotherapy can cause shrinkage of the tumor.

Patients affected by pain with type 5 or 6 lesions present an indication for vertebroplasty, alcohol ablation or surgery since the lesion is wide and involves parts of the vertebra in which the spinal stability is concerned; fixation and radiotherapy can be also considered after the procedure.

\section{Patients affected by neurological deficit}

Vertebroplasty, alcohol ablation or surgery followed or not by fixation and radiotherapy are proposed for patients affected by neurological deficit with a type 4, 5 or 6 lesion.

Vertebroplasty and alcohol ablation can be proposed if the neurological deficit is "minor" (radiculopathy) or it presents a slow progression.

Surgery with total or partial removal of the lesion is proposed for progressive neurological deficits.

Radiotherapy is not considered for patients with neurological deficit since of the unknown efficacy and rapidity on the tumoral tissue.

\section{Conclusion}

This is a proposal of a new algorithm of treatment for VHs. Now-a-days a wide range of treatment options are available for extensive or symptomatic lesions but there is no consensus in literature. In this algorithm the proposed treatments are related to the symptoms of the patient and the width/location of the tumor inside the vertebra. The Tomita classification of vertebral lesion is used to help the surgeon to identify the type of lesion. This is only a proposal and the algorithm has not been applied on a series of patients yet. Its application will eventually confirm its validity. Future multicenter studies able to provide management recommendations are warranted.

\section{Conflict of Interest}

The author states that there is no conflict of interest.

\section{References}

1. Acosta FL Jr, Sanai N, Cloyd J, Deviren V, Chou D, et al. (2011) Treatment of enneking stage 3 aggressive vertebral hemangiomas with intralesional spondylectomy: A report of 10 
cases and review of the literature. J Spinal Disord Tech 24: 268275.

2. Dang L, Liu C, Yang SM (2012) Aggressive vertebral hemangioma of the thoracic spine without typical radiological appearance. Eur Spine J 21: 1994-1999.

3. Fourney DR (2012) Expert's comment concerning Grand Rounds case entitled "Aggressive vertebral hemangioma of the thoracic spine without typical radiological appearance" Dang L, Liu C, Yang SM, Jiang L, Liu ZJ, Liu XG, Yuan HS, Wei F, Yu M (eds). Eur Spine J 21: 2000-2002.

4. Tarantino R, Donnarumma P, Nigro L, Delfini R (2015) Surgery in extensive vertebral hemangioma: Case report and literature review and a new algorithm proposal. Neurosurg Rev 38: 585-592.

5. Jiang L, Liu XG, Yuan HS (2014) Diagnosis and treatment of vertebral hemangiomas with neurologic deficit: A report of 29 cases and literature review. Spine J 14: 944-954.
6. Miszczyk L, Tukiendorf A (2012) Radiotherapy of painful vertebral hemangiomas: The single center retrospective analysis of 137 cases. Int J Radiat Oncol Biol Phys 82: e173-e180.

7. Sakata K, Hareyama M, Oouchi A (1997) Radiotherapy of vertebral hemangiomas. Acta Oncol 36: 719-724.

8. Heyd R, Seegenschmiedt MH, Rades D (2010) Radiotherapy for symptomatic vertebral hemangiomas: Results of a multicenter study and literature review. Int J Radiat Oncol Biol Phys 77: 217225.

9. Boschi V, Pogorelić Z, Gulan G, Perko Z, Grandić L, et al. (2011) Management of cement vertebroplasty in the treatment of vertebral hemangioma. Scand J Surg 100: 120-124.

10. Tomita K, Kawahara N, Kobayashi T, Yoshida A, Murakami H, et al. (2001) Surgical strategy for spinal metastases. Spine 26: 298-306. 